\title{
Food shopping transition: socio-economic characteristics and motivations associated with use of supermarkets in a North African urban environment
}

\author{
Sophie Tessier ${ }^{1, *}+$, Pierre Traissac ${ }^{1}$, Nicolas Bricas ${ }^{2}$, Bernard Maire ${ }^{1}$, \\ Sabrina Eymard-Duvernay ${ }^{1}$, Jalila El $\mathrm{Ati}^{3}$ and Francis Delpeuch ${ }^{1}$ \\ ${ }^{1}$ Mixed Research Unit 204 NUTRIPASS (IRD/Montpellier I/Montpellier II), Montpellier, France: ${ }^{2}$ Cirad, Mixed \\ Research Unit Moisa, Montpellier, France: ${ }^{3}$ National Institute of Nutrition (INNTA), Tunis, Tunisia
}

Submitted 7 August 2009: Accepted 4 February 2010: First published online 31 March 2010

\begin{abstract}
Objective: In the context of the nutrition transition and associated changes in the food retail sector, to examine the socio-economic characteristics and motivations of shoppers using different retail formats (large supermarkets (LSM), medium-sized supermarkets (MSM) or traditional outlets) in Tunisia.

Design: Cross-sectional survey (2006). Socio-economic status, type of food retailer and motivations data were collected during house visits. Associations between socio-economic factors and type of retailer were assessed by multinomial regression; correspondence analysis was used to analyse declared motivations. Setting: Peri-urban area around Tunis, Tunisia, North Africa.

Subjects: Clustered random sample of 724 households.

Results: One-third of the households used LSM, two-thirds used either type of supermarket, but less than 5\% used supermarkets only. Those who shopped for food at supermarkets were of higher socio-economic status; those who used LSM were much wealthier, more often had a steady income or owned a credit card, while MSM users were more urban and had a higher level of education. Most households still frequently used traditional outlets, mostly their neighbourhood grocer. Reasons given for shopping at the different retailers were most markedly leisure for LSM, while for the neighbourhood grocer the reasons were fidelity, proximity and availability of credit (the latter even more for lower-income customers).

Conclusions: The results pertain to the transition in food shopping practices in a south Mediterranean country; they should be considered in the context of growing inequalities in health linked to the nutritional transition, as they differentiate use and motivations for the choice of supermarkets $v$. traditional food retailers according to socio-economic status.
\end{abstract}

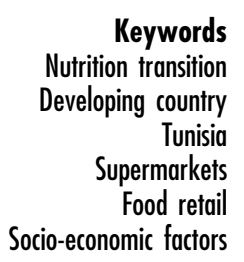

As a corollary of rapid economic development, middleincome countries are experiencing a rapid nutritional transition, featuring marked changes in diet and lifestyles ${ }^{(1)}$. In this context, major transformations in the food retail sector have been observed, including a sharp rise in the number of supermarkets ${ }^{(2)}$. In urban areas of developing countries, large-scale food retailers are tending to replace traditional markets, neighbourhood stores and street sellers; this process is referred to by some authors as 'supermarketisation', (3). Until recently attention

$\dagger$ Correspondence address: Institut de Recherche pour le Développement (IRD), UMR 204 'Nutripass', BP 64501, F-34394 Montpellier Cedex 5, France. was focused more on the potential consequences of such supermarketisation for the agricultural sector ${ }^{(4,5)}$, and the results of the few studies linking the development of supermarkets to possible changes in food shopping habits and dietary intake have been mixed. However, a recent comprehensive review of the dietary implications of supermarket development worldwide ${ }^{(6)}$ clearly showed that the continued development of supermarkets will have major implications.

Beyond the influence on food consumption for regular users, the implications of the development of supermarkets for dietary intake at the population level also depend on the prevalence of exposure to these retail outlets. Regarding this issue in developing countries, 
some authors ${ }^{(7,8)}$ have proposed a three-step model of diffusion in which supermarkets first appeal to upperincome consumers, then to the middle class and finally to the urban poor, because prices tend to drop as supermarkets continue to spread. However, in urban areas of developing countries, supermarkets currently appear to coexist alongside small-scale commercial outlets ${ }^{(9)}$, central food markets, neighbourhood stores and sellers of street food. Among the characteristics of supermarkets that have implications for consumers' diets are their location and format ${ }^{(6,10)}$. However, to our knowledge, no study has yet analysed the socio-economic characteristics of the shoppers who use these different retail formats.

Tunisia (a North African country) is experiencing major economic, epidemiological and nutritional changes ${ }^{(11,12)}$, with a rise in the number of modern supermarkets including the recent opening of two 'hypermarkets' in the vicinity of the capital city, Tunis. Building on a previous paper on the associations between supermarket use and dietary intake ${ }^{(13)}$, the objective of the present analyses was to examine the socio-economic characteristics of shoppers using different retail formats in Tunisia, and their motivations for doing so. The retail formats were large supermarkets, medium-sized supermarkets and traditional outlets.

\section{Methods}

\section{Study area}

Tunisia, a south Mediterranean country, is located between Algeria and Libya, has a population of 10 million and a middle level of development (ranked 91/177 on the Human Development Index composite scale in $2005^{(14)}$ ). Our study area was Greater Tunis, with about 2 million inhabitants $^{(15)}$. It is the most developed and urbanised area in Tunisia and has the most supermarkets. Medium- sized supermarkets have existed in Tunisia for decades, but since the beginning of the 2000s, a major change in the food retail landscape has taken place with the opening of two 'hypermarkets' in the Greater Tunis area. This has also had indirect results in that established supermarket chains have started opening new outlets as well as modernising their internal layout and sales practices ${ }^{(16)}$.

\section{Subjects}

A cross-sectional survey was conducted in NovemberDecember 2006 in Greater Tunis. Based on data from the 2004 census, the survey used a random, two-level (census area, household) clustered sample of households $^{(17)}$. In each household, the person in charge of main food shopping was interviewed.

\section{Data}

Part of the survey questionnaire was derived from a preliminary qualitative phase (face-to-face interviews and focus group discussions) to identify the relevant contextual information.

\section{Socio-economic characteristics}

Socio-economic and demographic data were collected at both individual and household levels (Table 1). An asset-based household economic level proxy was computed by multiple correspondence analysis ${ }^{(18)}$ from dwelling characteristics, utilities and appliances. The first principal component was used as a proxy of relative household wealth $^{(12,19)}$ and was used in analyses after breakdown into tertiles of increasing level (low, medium and high).

\section{Type of outlet used for main food shopping}

Although some analyses pertained to supermarkets, distinction was made between 'medium-sized supermarkets'

Table 1 Socio-economic and demographic characteristics of the sample, Greater Tunis, Tunisia, 2006

\begin{tabular}{|c|c|c|c|c|c|c|c|}
\hline Household & $n^{\star}$ & $\%+$ & SE & Person in charge of food shopping & $n^{*}$ & $\%+$ & SE \\
\hline Milieu & & & & Sex & & & \\
\hline Urban & 567 & $91 \cdot 9$ & $3 \cdot 0$ & Female & 573 & $78 \cdot 7$ & $1 \cdot 6$ \\
\hline Rural & 157 & $8 \cdot 0$ & $3 \cdot 0$ & Male & 151 & $21 \cdot 3$ & $1 \cdot 6$ \\
\hline Household size & & & & Age (years) & & & \\
\hline $1-4$ & 323 & $49 \cdot 6$ & $3 \cdot 0$ & $19-34$ & 152 & $20 \cdot 4$ & $1 \cdot 5$ \\
\hline 5 & 150 & $21 \cdot 5$ & $1 \cdot 9$ & $35-49$ & 308 & $41 \cdot 3$ & $2 \cdot 6$ \\
\hline $6-14$ & 250 & $28 \cdot 9$ & $3 \cdot 1$ & $50-89$ & 264 & $38 \cdot 2$ & $2 \cdot 6$ \\
\hline Economic index & & & & Level of education & & & \\
\hline Low & 314 & $34 \cdot 0$ & $4 \cdot 5$ & No schooling & 198 & $24 \cdot 0$ & $2 \cdot 5$ \\
\hline Medium & 234 & $34 \cdot 9$ & $2 \cdot 8$ & Primary & 265 & $32 \cdot 9$ & $2 \cdot 6$ \\
\hline High & 163 & $31 \cdot 1$ & $4 \cdot 3$ & Training/secondary/higher & 259 & $43 \cdot 1$ & $4 \cdot 0$ \\
\hline Steady income & & & & Matrimonial status & & & \\
\hline Yes & 445 & $68 \cdot 2$ & $3 \cdot 3$ & Married & 592 & $81 \cdot 7$ & $2 \cdot 0$ \\
\hline No & 279 & $31 \cdot 8$ & $3 \cdot 3$ & Other & 132 & $18 \cdot 4$ & $2 \cdot 0$ \\
\hline Credit card & & & & Occupation & & & \\
\hline Yes & 80 & $14 \cdot 7$ & $2 \cdot 4$ & Working & 214 & $32 \cdot 6$ & $2 \cdot 9$ \\
\hline No & 643 & $85 \cdot 3$ & $2 \cdot 4$ & Non-working & 510 & $67 \cdot 4$ & $2 \cdot 9$ \\
\hline
\end{tabular}

*Number of households surveyed.

tWeighted proportions. 
(MSM) and 'hypermarkets', i.e. 'large supermarkets' (LSM), according to their surface area $\left(\geq 10000 \mathrm{~m}^{2}\right.$ for LSM). One reason for the choice of this definition, among others $^{(16)}$, was because, beyond their surface area, hypermarkets in Greater Tunis differ from medium-sized supermarkets in that they are located in a shopping mall comprising a wide range of shops, cafés/cafeterias and a car park, offer a wider range of fresh food departments (catering, bread and pastries, butcher, fishmonger) and also have larger non-food departments. Finally, although supermarkets of medium size are quite evenly distributed throughout Greater Tunis, both hypermarkets are located in the outskirts of the area.

In this survey, 'grocers' (attar) are independent familyrun food outlets with a sales area of less than $50 \mathrm{~m}^{2}$ (reference (16)). The term 'market' refers to traditional open-air or covered markets in town centres or neighbourhoods with rows of retailers ${ }^{(6)}$.

The survey questionnaire included items for which interviewees were asked to rank in order of priority (1st, 2nd or 3rd) the three types of outlets where they most frequently did their main food shopping, and also, for supermarkets, included items regarding time and distance to the outlets. For each type of retail outlet (LSM, MSM, grocer, market), binary variables coded whether interviewees used that type of outlet for their main food shopping (regardless of the rank). From the variables pertaining to MSM and/or LSM, a three-category hierarchical variable was computed: never shopped at supermarkets/shopped at MSM only (regardless of other types of outlets but excluding LSM)/shopped at LSM (regardless of MSM or other type of outlets). For both MSM and LSM, easy access ( $v$. not) was defined as living less than $5 \mathrm{~km}$ or less than $30 \mathrm{~min}$ from a retail outlet.

\section{Reasons for using the different types of food outlet}

The questionnaire featured open questions, where subjects could state whatever reasons or motivations they associated with the use of each type of outlet. From the exhaustive list of answers, the twelve most frequently declared items were identified (Table 3 ) and used in the analyses.

\section{Data collection}

The questionnaire was translated into Arabic, pre-tested and validated with the target population. Subjects were interviewed at home by specially trained local nutritionists.

\section{Ethics}

The Tunisian National Statistical Council reviewed and approved the study (visa no. 11/2006). The surveyed subjects were informed of their right to refuse to take part and of the strict respect of the confidentiality of their answers, and gave their verbal consent to take part in the study.

\section{Data management and analysis}

Data entry, including quality checks and validation by double entry of questionnaires, was performed with EpiData version 3·1 (EpiData Association, Odense, Denmark). Data management was performed with the Stata statistical software package version 9.2 (StataCorp LP, College Station, TX, USA).

We assessed the associations between the multinomial response variable coding shopping at supermarkets (LSM, MSM or never) and socio-economic variables using multivariate multinomial logit regression models ${ }^{(20)}$. The strength of (crude or adjusted) associations was assessed by relative risk ratios, using 'never' as the reference response variable category. Correspondence analysis was used for analysis of associations between the type of retail outlet and reasons stated for their use ${ }^{(18)}$.

All analyses took into account characteristics of the sampling design ${ }^{(21)}$ (clustering, sampling weights also including a post-stratification on sex, age and urban $v$. rural) using the appropriate svy commands of the Stata software. The complete-case analysis method was used to deal with missing data. Results are given as the estimate with its design-based standard error or confidence interval. The first type error rate was set at 0.05 for all analyses.

\section{Results}

\section{Socio-economic characteristics}

From a total of 753 households that were to be included in the study, 724 households were actually surveyed. Most (Table 1) were from an urban area and mean household size was $4 \cdot 7$ ( $\operatorname{se} 0 \cdot 1 ; n$ 723). One-third of the households (data not shown) declared they owned a car. Two-thirds of the households declared they had a steady income, but only a minority declared they owned a credit card. Those in charge of food shopping were predominantly female; the mean age was $46 \cdot 2$ (se $0 \cdot 6$ ) years, most were married; $24.0 \%$ had no schooling at all, while $43 \cdot 1 \%$ had reached secondary level or higher; the majority $(67.4 \%)$ said they did not work outside the home.

\section{Type of outlet used for main food shopping}

Out of the total of 724 households, $58 \cdot 8$ ( $\mathrm{se} 4 \cdot 3$ ) \% used supermarkets for their main food shopping (LSM and/or MSM), but only 27.3 (se 3.6) \% declared using LSM (regardless of MSM, grocer or market) and $32 \cdot 2$ (se $2 \cdot 9) \%$ used only MSM (i.e. regardless of grocer and market but excluding LSM). Finally, only $4 \cdot 5$ (SE 1.3 ) \% of households used only supermarkets for their main food shopping. Concerning time and distance $(n 711), 74 \cdot 1$ (sE $4 \cdot 2) \%$ had 'easy access' to MSM $v .23 .9$ (sE 4.5 ) \% only to LSM. Most households, $93 \cdot 8$ (sE $1 \cdot 6$ ) \%, used their nearby grocer and $26 \cdot 5$ (SE $2 \cdot 8$ ) \% used the market. 
Table 2 Associations of socio-economic characteristics with use of large (LSM) or medium-sized supermarkets (MSM) for main food shopping, Greater Tunis, Tunisia, 2006 ( $n$ 703)

\begin{tabular}{|c|c|c|c|c|c|c|c|c|c|c|c|}
\hline \multirow[b]{3}{*}{ Socio-economic characteristic } & \multirow[b]{3}{*}{$n^{\star}$} & \multicolumn{7}{|c|}{ Unadjusted associations } & \multicolumn{3}{|c|}{ Adjusted associationst } \\
\hline & & \multicolumn{3}{|c|}{ Never‡ MSM only§ LSM\| } & \multicolumn{2}{|c|}{ MSM only $v$. Never } & \multicolumn{2}{|c|}{ LSM $v$. Never } & \multicolumn{2}{|c|}{ MSM only $v$. Never } & \multirow{2}{*}{$\frac{\text { LSM } v . \text { Never }}{\text { RRR } 95 \% \mathrm{Cl}}$} \\
\hline & & \multicolumn{3}{|c|}{ Weighted \% } & \multirow[t]{2}{*}{ RRR } & \multirow[t]{2}{*}{$95 \% \mathrm{Cl}$} & \multirow[t]{2}{*}{ RRR } & \multirow[t]{2}{*}{$95 \% \mathrm{Cl}$} & \multirow[t]{2}{*}{ RRR } & \multirow[t]{2}{*}{$95 \% \mathrm{Cl}$} & \\
\hline All & 703 & $40 \cdot 8$ & $31 \cdot 9$ & $27 \cdot 3$ & & & & & & & \\
\hline \multicolumn{12}{|l|}{ Household } \\
\hline Milieu & & & & & \multicolumn{4}{|c|}{$P<0.0001$} & \multicolumn{3}{|c|}{$P=0.0004$} \\
\hline Urban & 550 & $36 \cdot 5$ & $34 \cdot 2$ & $29 \cdot 3$ & $15 \cdot 5$ & $6 \cdot 5,36 \cdot 8$ & $14 \cdot 2$ & $3 \cdot 3,61 \cdot 7$ & $6 \cdot 4$ & $2 \cdot 7,15 \cdot 1$ & $1 \cdot 60 \cdot 2,9 \cdot 7$ \\
\hline Rural & 153 & $89 \cdot 5$ & $5 \cdot 4$ & $5 \cdot 1$ & $1 \cdot 0$ & - & $1 \cdot 0$ & - & $1 \cdot 0$ & - & $1 \cdot 0 \quad-$ \\
\hline Household size & & \multicolumn{7}{|c|}{$P<0.0001$} & \multicolumn{3}{|c|}{$P=0.0071$} \\
\hline $1-4$ & 308 & $30 \cdot 4$ & $34 \cdot 9$ & $34 \cdot 7$ & $2 \cdot 5$ & $1 \cdot 5,4 \cdot 3$ & $6 \cdot 0$ & $3 \cdot 0,11 \cdot 8$ & $1 \cdot 7$ & $0 \cdot 9,3 \cdot 1$ & $3 \cdot 21 \cdot 6,6 \cdot 5$ \\
\hline 5 & 150 & $37 \cdot 5$ & $30 \cdot 7$ & $31 \cdot 8$ & $1 \cdot 8$ & $1 \cdot 0,3 \cdot 3$ & $4 \cdot 5$ & $2 \cdot 3,8 \cdot 7$ & $1 \cdot 0$ & $0.5,1 \cdot 9$ & $2 \cdot 10 \cdot 9,5 \cdot 3$ \\
\hline $6-14$ & 245 & $60 \cdot 9$ & $27 \cdot 5$ & $11 \cdot 6$ & $1 \cdot 0$ & - & $1 \cdot 0$ & - & $1 \cdot 0$ & - & $1 \cdot 0-$ \\
\hline Economic level proxy & & \multicolumn{7}{|c|}{$P<0.0001$} & & $P<0.00$ & 001 \\
\hline Low & 311 & $69 \cdot 9$ & $25 \cdot 2$ & 4.9 & $1 \cdot 0$ & - & $1 \cdot 0$ & - & $1 \cdot 0$ & - & $1 \cdot 0$ \\
\hline Medium & 231 & $36 \cdot 3$ & $35 \cdot 7$ & $28 \cdot 0$ & $2 \cdot 7$ & $1 \cdot 5,5 \cdot 0$ & $11 \cdot 1$ & $5 \cdot 2,23 \cdot 8$ & $1 \cdot 3$ & $0 \cdot 7,2 \cdot 5$ & $5 \cdot 22 \cdot 3,12 \cdot 2$ \\
\hline High & 161 & $14 \cdot 0$ & $34 \cdot 8$ & $51 \cdot 2$ & 6.9 & $3 \cdot 6,13 \cdot 4$ & $52 \cdot 7$ & $25 \cdot 1,110 \cdot 3$ & $2 \cdot 3$ & $1 \cdot 1,4 \cdot 4$ & $17 \cdot 08 \cdot 1,35 \cdot 5$ \\
\hline Steady income & & & & & $P<0.0$ & & & & & $P=0.0$ & 031 \\
\hline Yes & 431 & $30 \cdot 9$ & $35 \cdot 2$ & $33 \cdot 9$ & $2 \cdot 9$ & $1 \cdot 8,4 \cdot 6$ & $5 \cdot 1$ & $2 \cdot 7,9 \cdot 7$ & $2 \cdot 0$ & $1 \cdot 1,3 \cdot 5$ & $2 \cdot 21 \cdot 1,4 \cdot 6$ \\
\hline No & 272 & $62 \cdot 0$ & $24 \cdot 6$ & $13 \cdot 4$ & $1 \cdot 0$ & - & $1 \cdot 0$ & - & $1 \cdot 0$ & - & $1 \cdot 0-$ \\
\hline Credit card & & & & & $P<0.0$ & & & & & $P=0.0$ & 013 \\
\hline Yes & 76 & $10 \cdot 7$ & $26 \cdot 2$ & $63 \cdot 1$ & $3 \cdot 4$ & $1 \cdot 6,7 \cdot 6$ & $12 \cdot 8$ & $5 \cdot 5,29 \cdot 7$ & $1 \cdot 1$ & $0 \cdot 5,2 \cdot 5$ & $2 \cdot 61 \cdot 2,5 \cdot 6$ \\
\hline No & 627 & $45 \cdot 9$ & $32 \cdot 8$ & $21 \cdot 3$ & $1 \cdot 0$ & - & $1 \cdot 0$ & - & $1 \cdot 0$ & - & $1 \cdot 0-$ \\
\hline Easy access to supermarket & & & & & $P<0.0$ & & & & & $P=0.0$ & \\
\hline Yes & 472 & $32 \cdot 0$ & $35 \cdot 6$ & $32 \cdot 4$ & $3 \cdot 7$ & $2 \cdot 0,7 \cdot 0$ & $6 \cdot 0$ & $2 \cdot 9,12 \cdot 3$ & $1 \cdot 7$ & $0 \cdot 8,3 \cdot 3$ & $2 \cdot 51 \cdot 1,5 \cdot 3$ \\
\hline No & 231 & $68 \cdot 1$ & $20 \cdot 4$ & $11 \cdot 5$ & $1 \cdot 0$ & - & $1 \cdot 0$ & - & $1 \cdot 0$ & - & $1 \cdot 0-$ \\
\hline Person shopping for food & & & & & & & & & & & \\
\hline Sex & & & & & $P=0$. & & & & & $P=0.4$ & \\
\hline Women & 554 & $41 \cdot 1$ & $30 \cdot 6$ & $28 \cdot 3$ & $0 \cdot 8$ & $0 \cdot 5,1 \cdot 3$ & $1 \cdot 1$ & $0 \cdot 6,2 \cdot 1$ & $1 \cdot 1$ & $0 \cdot 6,2 \cdot 1$ & $1 \cdot 80 \cdot 7,4 \cdot 5$ \\
\hline Men & 149 & $39 \cdot 7$ & $36 \cdot 4$ & $23 \cdot 9$ & $1 \cdot 0$ & - & $1 \cdot 0$ & - & $1 \cdot 0$ & - & $1 \cdot 0 \quad-$ \\
\hline Age (years) & & & & & $P=0$. & & & & & $P=0 \cdot 1$ & \\
\hline $19-34$ & 147 & $38 \cdot 2$ & $27 \cdot 8$ & $34 \cdot 0$ & $1 \cdot 0$ & - & $1 \cdot 0$ & - & $1 \cdot 0$ & - & $1 \cdot 0$ \\
\hline $35-49$ & 299 & $36 \cdot 4$ & $35 \cdot 7$ & $27 \cdot 9$ & $1 \cdot 4$ & $0 \cdot 8,2 \cdot 3$ & 0.9 & $0.5,1.5$ & $1 \cdot 5$ & $0 \cdot 8,2 \cdot 9$ & $0.70 .3,1 \cdot 4$ \\
\hline $50-89$ & 257 & $47 \cdot 0$ & $29 \cdot 8$ & $23 \cdot 2$ & 0.9 & $0.5,1.5$ & 0.6 & $0 \cdot 3,1 \cdot 2$ & $1 \cdot 2$ & $0 \cdot 6,2 \cdot 5$ & $0.60 .3,1.5$ \\
\hline Matrimonial status & & & & & $P=0$. & & & & & $P=0.9$ & \\
\hline Married & 131 & $42 \cdot 8$ & $31 \cdot 6$ & $25 \cdot 6$ & 0.9 & $0.5,1 \cdot 6$ & 0.9 & $0.5,1.5$ & 0.9 & $0 \cdot 6,1 \cdot 6$ & $1 \cdot 00 \cdot 5,1 \cdot 8$ \\
\hline Other & 572 & $40 \cdot 4$ & $31 \cdot 9$ & $27 \cdot 7$ & $1 \cdot 0$ & - & $1 \cdot 0$ & - & $1 \cdot 0$ & - & $1.0 \quad-$ \\
\hline Level of education & & & & & $P<0.0$ & & & & & $P=0.00$ & 004 \\
\hline No schooling & 195 & $70 \cdot 4$ & $17 \cdot 8$ & $11 \cdot 8$ & $1 \cdot 0$ & - & $1 \cdot 0$ & - & $1 \cdot 0$ & - & $1 \cdot 0$ \\
\hline Primary & 260 & $50 \cdot 9$ & $32 \cdot 1$ & $17 \cdot 0$ & $2 \cdot 5$ & $1 \cdot 4,4 \cdot 3$ & $2 \cdot 0$ & $1 \cdot 0,3 \cdot 8$ & $2 \cdot 4$ & $1 \cdot 3,4 \cdot 5$ & $1 \cdot 20 \cdot 6,2 \cdot 7$ \\
\hline Secondary or higher & 248 & $16 \cdot 4$ & $39 \cdot 5$ & $44 \cdot 1$ & $9 \cdot 5$ & $5 \cdot 4,16 \cdot 7$ & $16 \cdot 0$ & $7 \cdot 2,35 \cdot 4$ & $6 \cdot 0$ & $2 \cdot 8,12 \cdot 7$ & $3.41 \cdot 2,9 \cdot 4$ \\
\hline Occupation & & & & & $P=0.0$ & & & & & $P=0.6$ & \\
\hline Working & 209 & $28 \cdot 9$ & $35 \cdot 0$ & $36 \cdot 1$ & 1.9 & $1 \cdot 2,2 \cdot 9$ & $2 \cdot 5$ & $1 \cdot 4,4 \cdot 7$ & $1 \cdot 1$ & $0 \cdot 6,2 \cdot 2$ & $1 \cdot 60 \cdot 6,4 \cdot 2$ \\
\hline Non-working & 494 & $46 \cdot 7$ & $30 \cdot 3$ & $23 \cdot 0$ & $1 \cdot 0$ & - & $1 \cdot 0$ & - & $1 \cdot 0$ & - & $1 \cdot 0 \quad-$ \\
\hline
\end{tabular}

RRR, relative risk ratio.

${ }^{*}$ Complete-case analysis: subjects with no missing values for neither of the socio-economic cofactors ( $n$ 703).

tAdjusted for all variables in column 1.

†Response variable reference category: never uses neither MSM nor LSM for main food shopping.

$\S$ Uses MSM for main food shopping, regardless of grocer and traditional market but excluding LSM.

\|Uses LSM, regardless of grocer, traditional market and MSM.

\section{Socio-economic factors associated witb shopping at supermarkets}

Results of multinomial regression models are presented in Table 2 ( $n$ 703, complete-case analysis subsample). Crude associations showed that urban households were much more likely to shop at both MSM and LSM $v$. never, but in adjusted analyses the association persisted only for MSM. That small households shopped more at MSM $v$. never in unadjusted analysis did not stand the adjustment but persisted somewhat for shopping at LSM (linear trend $P=0 \cdot 001)$. For MSM, the sizeable unadjusted association with the economic level of the household was drastically reduced by the adjustment; conversely, the spectacularly strong unadjusted association between likelihood of shopping at LSM and increasing economic level, though reduced, was still remarkable once the confounding of other socio-economic variables was taken into account. Households with a steady income, a credit card or easy access were twice as likely to shop at MSM $v$. never, but when adjusted only steady income was still associated; for shopping at LSM $v$. never, unadjusted associations were stronger for steady income, owning a credit card and easy access, but although still significant, were much reduced after adjustment, indicating that their effect was greatly (though not entirely) confounded by other socio-economic variables. 
Table 3 Reasons stated for choice of type of food retail outlet, Greater Tunis, Tunisia, 2006 ( $n$ 724)

\begin{tabular}{|c|c|c|c|c|c|c|c|c|}
\hline & \multicolumn{8}{|c|}{ Type of food retail outlet } \\
\hline & \multicolumn{2}{|c|}{$\begin{array}{c}\text { LSM } \\
(n 163)^{*}\end{array}$} & \multicolumn{2}{|c|}{$\begin{array}{c}\text { MSM } \\
(n 297)^{\star}\end{array}$} & \multicolumn{2}{|c|}{$\begin{array}{l}\text { Nearby grocer } \\
\quad(n 697)^{\star}\end{array}$} & \multicolumn{2}{|c|}{$\begin{array}{l}\text { Traditional market } \\
(n \text { 191 })^{\star}\end{array}$} \\
\hline & $\%+$ & SE & $\%+$ & $\mathrm{SE}$ & $\%+$ & SE & $\% \dagger$ & SE \\
\hline \multicolumn{9}{|l|}{ Products } \\
\hline Quality-choice & $58 \cdot 0$ & 5.9 & $49 \cdot 8$ & $3 \cdot 1$ & $12 \cdot 6$ & $1 \cdot 5$ & $52 \cdot 5$ & $4 \cdot 4$ \\
\hline Good prices/promotions & $41 \cdot 1$ & $4 \cdot 4$ & $44 \cdot 5$ & $3 \cdot 6$ & $4 \cdot 0$ & $1 \cdot 1$ & $37 \cdot 1$ & $4 \cdot 5$ \\
\hline \multicolumn{9}{|l|}{ Store } \\
\hline Proximity & $16 \cdot 1$ & $4 \cdot 6$ & $39 \cdot 4$ & $3 \cdot 1$ & $82 \cdot 9$ & $2 \cdot 3$ & $71 \cdot 6$ & $3 \cdot 7$ \\
\hline Spacious-clean & $1 \cdot 2$ & $0 \cdot 8$ & $2 \cdot 7$ & $0 \cdot 8$ & $1 \cdot 0$ & $0 \cdot 4$ & $1 \cdot 3$ & 0.9 \\
\hline Car park & 0.0 & - & $2 \cdot 1$ & $2 \cdot 1$ & 0.0 & - & 0.0 & - \\
\hline Availability of credit & $0 \cdot 0$ & - & 0.9 & 0.5 & $23 \cdot 7$ & $2 \cdot 7$ & $1 \cdot 2$ & 0.1 \\
\hline Convenient & 0.0 & - & 0.3 & 0.3 & 0.6 & $0 \cdot 4$ & $1 \cdot 8$ & $1 \cdot 3$ \\
\hline \multicolumn{9}{|l|}{ Shopping } \\
\hline Leisure & $30 \cdot 4$ & $4 \cdot 8$ & $6 \cdot 4$ & $1 \cdot 8$ & $0 \cdot 1$ & $0 \cdot 1$ & $2 \cdot 3$ & $1 \cdot 1$ \\
\hline Fidelity & $2 \cdot 1$ & $1 \cdot 2$ & $2 \cdot 8$ & $1 \cdot 1$ & $13 \cdot 7$ & $1 \cdot 6$ & $3 \cdot 7$ & $1 \cdot 4$ \\
\hline Emergency shopping & $2 \cdot 0$ & 1.9 & 3.9 & $1 \cdot 3$ & $13 \cdot 6$ & $2 \cdot 3$ & $1 \cdot 3$ & $1 \cdot 0$ \\
\hline Freedom of choice & 0.8 & 0.8 & $2 \cdot 2$ & 0.8 & 0.0 & & $5 \cdot 4$ & $2 \cdot 2$ \\
\hline Daily shopping & 0.0 & - & 0.3 & 0.3 & 1.5 & 0.5 & 1.6 & $1 \cdot 1$ \\
\hline
\end{tabular}

LSM, large supermarket; MSM, medium-sized supermarket.

*Number of persons (among the 724 surveyed) using type of outlet for main food shopping.

tWeighted proportions.

Concerning the characteristics of the person in charge of food shopping, age was not associated with use of MSM or LSM either before or after adjustment, even if the effect of the adjustment was towards more use of supermarkets by younger people. Neither the sex nor the marital status of the person in charge of food shopping was associated with the use of supermarkets. In unadjusted analyses, a high education level was clearly associated with shopping at MSM and even more for LSM; however, once adjusted, a strong independent association with education level only persisted for MSM, while it was much reduced for LSM (twice lower than for MSM). The observed unadjusted association with the professional occupation of the person was mostly confounded by other socio-economic variables.

Regarding access issues, additional analyses were also performed to specifically try to assess associations of supermarket use with car ownership (detailed data not shown). Unadjusted analysis revealed that it was indeed more associated with LSM than MSM use but its effect was entirely confounded by socio-economic variables.

\section{Reasons for choice of type of retail outlet}

Table 3 lists weighted percentages pertaining to the reasons (rows) given by users for their choice of a specific type of retail outlet (columns). Out of the twelve items, only two pertained to the food products themselves. An equal number of five items was related to characteristics of the store or the shopping itself; among these items, proximity was most often quoted by retail category but also over the whole sample of subjects. Figure 1 displays the combined rows/columns on the two first axes of the correspondence analysis of the choice data. The first and second axis account for respectively $77 \cdot 1 \%$ and $18 \cdot 5 \%$ of total inertia, so that the residual information not taken into account is minor; the high percentage of inertia on the first axis and the typical 'horseshoe' shape of the mapping indicate a mostly one-dimensional structure. Contributions to inertia (data not shown) on the first axis of row and column points revealed that the salient feature was that the subjects contrasted 'large supermarkets' (chosen for the 'leisure' dimension of shopping there but not their 'proximity') $v$. the 'nearby grocer' (chosen mainly because of 'availability of credit', and 'proximity' but also 'emergency shopping' and 'fidelity', but not 'good prices' and not 'quality choice'). Contrasts observed on axis two (details not shown) resulted in a much lower level of information indicating that markets were quoted as being differentially chosen $v$. all other types of retail because of 'freedom of choice', $v$. 'large supermarkets' because of their 'proximity', and $v$. 'grocer' because of their 'good prices'. It should be noted that reasons for the choice of 'medium supermarkets' were not very distinct, their profile being intermediary between 'large supermarkets' and other retail outlets.

Variations around these overall trends were observed according to socio-economic characteristics (detailed data not shown). There was a strong decreasing relationship between household economic level and likelihood of quoting credit as a reason for shopping at the nearby grocer $(40.0(\operatorname{se} 3.5) \%, 18 \cdot 8$ ( $\operatorname{se~} 2 \cdot 6) \%$ and $8 \cdot 8$ (se $2 \cdot 5$ ) \% for the lower, middle and higher tertile of economic level, respectively, $n$ 685, $P<0 \cdot 0001$ ). Conversely, the probability of declaring using the nearby grocer for emergency food shopping increased with economic level $(4 \cdot 2(\mathrm{SE} 1 \cdot 9) \%, 13 \cdot 3(\mathrm{SE} 2 \cdot 5) \%$ and $25 \cdot 2$ (SE $5 \cdot 2) \%$ for the first, second and third tertile, respectively, $n$ 685, $P=0 \cdot 0001)$. 


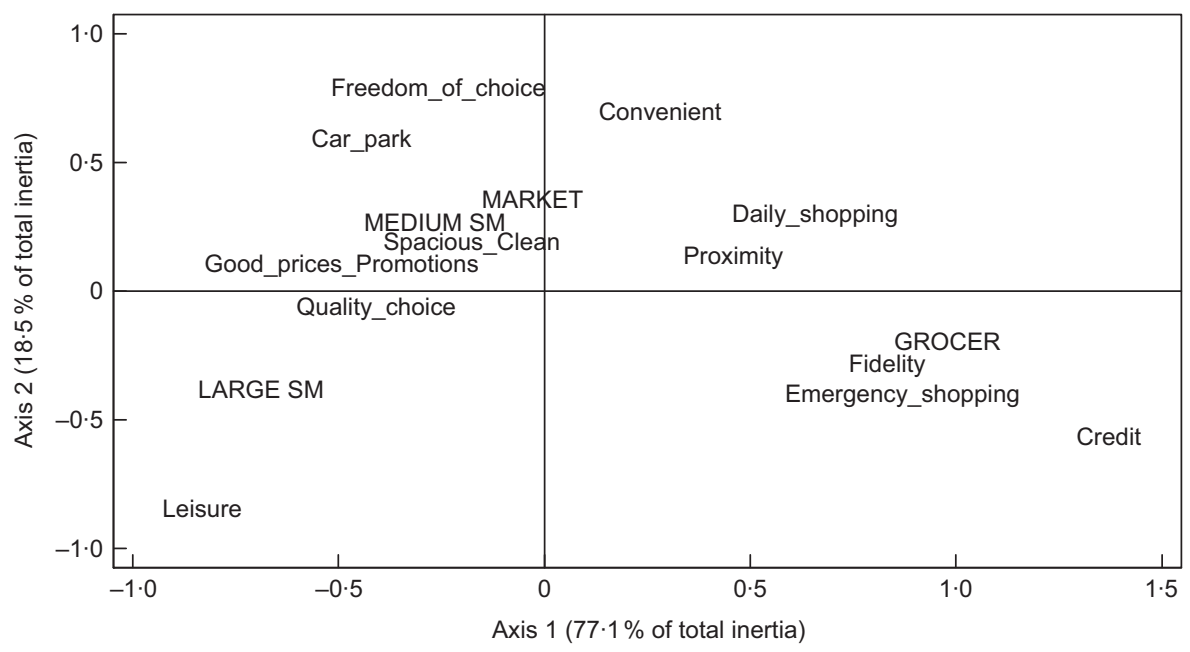

Fig. $1 \mathrm{Bi}$-plot of the first two axes of the correspondence analysis of reasons stated for the choice of type of food outlet, Greater Tunis, Tunisia, 2006. Labels are centred on $(x, y)$ coordinates; SM, supermarket

\section{Discussion}

In the context of a rapidly evolving nutritional transition and major changes in lifestyle, the present study assessed the relative importance of different types of food retailer (modern and traditional), the socio-economic profiles of consumers and the reasons behind the choice of the different types of outlets in Greater Tunis.

Concerning the overall use of supermarkets, while MSM were used by half the households, only just over a quarter of these consumers also used LSM. As expected, sharp contrasts between areas and socio-economic categories were observed as well as differences according to the type of outlet. A strong association was found with urban area only for supermarkets of medium size but not for large ones, but results pertaining to urban $v$. rural households should not be overemphasised given the mostly urban nature of the study population: the impact of supermarkets on peripheral rural areas warrants further research. Nevertheless, this result is not entirely surprising given the intraurban location of MSM in the district of Tunis $v$. more peripheral LSM. It also underlines the existence, all other things being equal, of location issues specific to the type of supermarket (rather independently of other socioeconomic factors, proximity was much more often quoted as a reason for the choice of MSM than for LSM).

Regarding the inverse association between small household size and LSM use, it is likely related to a combination of more 'modern' socio-cultural values (in relation with the demographic transition but also cultural values, e.g. whether or not several generations still live under the same roof) as well as the higher socioeconomic status of smaller households in the context. Although adjustment did reduce the strength of the association by half, it was still quite sizeable, especially for the smaller households; adjustment for socio-economic factors likely only partly accounts for the socio-cultural factors that underlie the relationship between the use of LSM and the size of the household. Concerning household socio-economic level, once adjusted, LSM use was shown to increase drastically with overall household wealth while the association was much weaker for MSM. Having a steady income was found to be independently associated with the use of both types of supermarkets. Having a credit card and easy access to supermarkets were quite specifically associated with LSM but nevertheless strongly confounded by other socio-economic factors (mostly household wealth). For these three factors, the association was nevertheless weak compared with household overall wealth. Among all the characteristics of the person in charge of food shopping, only a specific effect of a higher level of education was clearly associated with shopping at supermarkets, and the association was much stronger for medium-sized than large supermarkets. Concerning age, once adjusted for socioeconomic confounders, associations with age were in line with the hypothesis that shopping at supermarkets and especially LSM would be more frequent among younger customers; but conditional on size of the sample, this could not be inferred to the study population.

Thus, overall, we found that the use of supermarkets is more frequent among socio-economically privileged and more educated consumers in Greater Tunis. This suggests that, in the Tunis area, although supermarkets have been there for a long time, supermarket development is still only at the first step of the model of diffusion. This contrasts with Kenya, a low-income country where $60 \%$ of the $30 \%$ poorest consumers shop at supermarkets ${ }^{(22)}$. Given the three-step diffusion model, this implies that there are context-specific diffusion issues, either cultural or linked to different levels of economic development, or to the relative characteristics of the other types of 
food retail outlets. It could also be that, in Greater Tunis, MSM and LSM are not at the same stage of diffusion. If we consider that MSM and LSM have in common selfservice and differ mainly in their surface area, we could have expected fewer differences between consumer profiles in the two types of retailers. Yet, as indicated by the striking difference between MSM and LSM consumer profiles according to household economic level, we can hypothesise that LSM are at an earlier stage of the supermarkets' diffusion model than MSM, the latter being, at the same moment in time and in the same town, at a more advanced stage. It could also be that, rather independently of the three-step model, MSM and LSM have and will always have their specific consumers, with specific motivations (e.g. leisure for LSM).

Another salient point of our results is that although for a tiny minority of consumers $(4 \cdot 2 \%)$ the main shopping place is supermarkets to the exclusion of all other types of retail outlet, most households still shop at their neighbourhood grocer, whether or not they shop at supermarkets. This suggests that food shopping practices in Greater Tunis are in a transition stage with a combination of both modern and traditional retail food outlets. Indeed at the national level, even if modern supermarkets are increasing in concentration and popularity, the bulk of Tunisian food retailing is still dominated by small neighbourhood grocery shops ${ }^{(23)}$ of which there are around 250000 in the whole country. These shops are evenly distributed, including in strictly residential neighbourhoods that otherwise feature no commercial activity, so that most inhabitants of our study area are within short walking distance from an attar.

The fact that food shopping still relies heavily on more traditional types of outlet is all the more true for shoppers whose socio-economic status is low, of whom only $4.9 \%$ were found to use hypermarkets and only about a quarter to use MSM in addition to shopping at their local grocer or market. Overall, the reason that most contrasted the choice of grocers $v$. other types of retail was 'availability of credit'. In other contexts (Brazil and China), it has been shown that supermarkets are starting to offer consumers credit cards and even banking services ${ }^{(24)}$ but in our study area, availability of credit was very clearly quoted mostly only for the neighbourhood grocer. Regarding incomespecific differences pertaining to the importance of the availability of credit, households of the lower tertile of economic level were five times more likely to quote this reason for their choice of grocer than those of the higher tertile. This may seem paradoxical, since purchasing food in small quantities from local retailers on a daily basis generally costs more ${ }^{(25)}$, and this feature also stood out in the present study as the neighbourhood grocer was the type of retailer by far the least likely to be associated with good prices or promotions. Nevertheless, for the poorest consumers, the local grocery shop is the main and probably only place where they buy food due to lack of a sufficient steady income (which has been shown to be more associated with supermarket use) despite the fact that, regarding the food products, this type of outlet is much less frequently associated with good quality choice than the other three types of retailers. Interestingly, households from the higher income tertile were six times as likely as the lower textile to quote 'emergency shopping' as a reason for using the attar, indicating that although this type of retail outlet is widely used by all categories of households, the reasons for doing so are very different.

In addition to financial matters, it was also shown that traditional food retail fulfils social functions, as consumers are still attached to their personal relationship with their local shopkeeper; indeed, this system better meets consumer's social and cultural expectations by allowing them to increase their contact with the outside world in a way that the modern distribution system cannot ${ }^{(8,26)}$. Although the latter dimension was not directly assessed in our study, the fact that fidelity was much more often quoted as a reason for shopping at the attar $v$. other types of food retail is likely related to these social and psychological co-factors.

The development of supermarkets is indeed an issue that concerns the diet of high- or middle-income consumers in our study area. Nevertheless, the almost exclusive use of street corner stores for food shopping by lower-income consumers is also an issue. In other settings, some authors have described the emergence of urban 'food deserts,' deprived areas where low-income people have poor access to whole foods e.g. to fruit and vegetables, with probable negative consequences for health ${ }^{(27,28)}$. The main underlying factors are wealthier people moving from the centre towards the suburbs and with them the supermarkets that used to be located in the city centres. The situation is currently somewhat different in our study area as both traditional markets and many of the medium-sized supermarkets are still located in the downtown area. But this may change over time and indeed, despite the rise of supermarkets, the importance of corner stores should not be overlooked, e.g. for nutrition interventions targeted through the food retail sector $^{(29-31)}$.

Regarding the characteristics of the study, its strengths are that the questionnaire was based on a preliminary in-depth qualitative study, that it featured detailed analyses according to the different types of supermarkets and food retail outlets and conducted a detailed assessment and analysis of the motivations behind the choice of the different types of outlets. As for its limitations, one is the cross-sectional design of the survey, which always makes it difficult to interpret observed associations as causal even when care is taken to adjust for relevant confounders $^{(32)}$. The quantitative analysis of declared motivations would have needed to be completed by exploring complex items in more detail (such as 
'quality-choice' which could be interpreted differently depending on the type of product it actually refers to). Generalisability issues are always of importance. However, although a small country, Tunisia is emblematic both of fast emerging developing countries from an economic/development point of view, and also of a wide range of south and east Mediterranean countries that share societal and cultural issues. Nevertheless, the results of the present study regarding socio-economic characteristics associated with use of the different type of food retails outlets, though partly similar to those observed in Madagascar ${ }^{(33)}$, do differ from those in observed in Kenya ${ }^{(22)}$, Brazil ${ }^{(24)}$ and Guatemala ${ }^{(34)}$. These results show that supermarketisation in the developing world does not operate homogeneously and does not have the same effects in every country. Moreover, our results based on a cross-sectional analysis in 2006 are time-specific and whether or not the current trend in supermarketisation in developing countries will persist is an open question ${ }^{(33)}$.

In emerging countries, in the context of major economic and societal changes, changes in the food retail sector, including the rapid development of supermarkets, have been shown to have consequences for dietary intakes. Nevertheless, studies providing evidence regarding consumers' motivations as well as socio-economic profiles with respect to the type of food outlet for food shopping are rare in south Mediterranean countries. The present study is thus pioneering with respect to changes in food shopping attitudes and practices linked to the modernisation of food retailing in this context. Indeed, we derived substantiated results regarding the actual influence on food shopping habits: (i) the overall limited use of supermarkets by the study population; (ii) the still predominant role of neighbourhood grocers whether or not combined with supermarket use depending on socioeconomic status; (iii) the differential socio-economic profiles of customers of the different types of supermarkets; and (iv) the reasons that motivate use of the different types of outlet. South and east Mediterranean countries are experiencing a fast evolving nutrition transition where obesity and nutrition-related non-communicable diseases are becoming prevalent also among the lower socioeconomic strata ${ }^{(12)}$. In this context, it could seem feasible and cost-effective for those in charge of nutrition policies to address this issue by implementing nutrition interventions (e.g. financial incentives, nutrition education, promotion of 'healthy' products, informative labelling) only through centralised types of retail such as supermarkets. But the results of the present study underline that such interventions would likely both not cover a significant part of the population and mainly reach only customers of higher socio-economic status, with thus the risk of increasing inequalities regarding food consumption and nutrition-related non-communicable diseases instead of reducing them.

\section{Acknowledgements}

This work was funded by the French Nutrition Society (SFN) in the form of a research prize awarded to S.T., IRD, and benefited from the TAHINA project (Transition and Health Impact in North Africa INCO-MED no. ICA3-200110015): sampling frame, field logistics. All co-authors have no conflict of interest to declare. S.T. was involved in all steps of the research, from the study design, data collection, management and analysis to being responsible for writing the manuscript. P.T. was involved in data management and analyses, interpretation of results and the writing of the manuscript. N.B., B.M. and F.D. were involved in the study design, contributed to data analysis and interpretation of results, and helped write the manuscript. S.E.-D. contributed to data management and helped edit the manuscript. J.E.L. contributed to data collection and entry and helped edit the manuscript. The authors wish to thank all members of the INNTA nutrition team for their valuable contribution to fieldwork and data entry.

\section{References}

1. Popkin B \& Gordon-Larsen P (2004) The nutrition transition: worldwide obesity dynamics and their determinants. Int J Obes Relat Metab Disord 28, Suppl. 3, S2-S9.

2. Reardon T, Timmer CP, Barrett CB et al. (2003) The rise of supermarkets in Africa, Asia, and Latin America. Am J Agric Econ 85, 1140-1146.

3. Traill WB (2006) The rapid rise of supermarkets? Dev Policy Rev 24, 163-174.

4. Codron JM, Boushina Z, Fort F et al. (2004) Supermarkets in low-income Mediterranean countries: impacts on horticulture systems. Dev Policy Rev 22, 587-602.

5. Weatherspoon DD \& Reardon T (2003) The rise of supermarkets in Africa: implications for agrifood systems and the rural poor. Dev Policy Rev 21, 333-356.

6. Hawkes C (2008) Dietary implications of supermarket development: a global perspective. Dev Policy Rev 26, 657-692.

7. Reardon $\mathrm{T} \&$ \& Berdegue JA (2002) The rapid rise of supermarkets in Latin America: challenges and opportunities for development. Dev Policy Rev 20, 371-388.

8. Goldman A, Ramaswami S \& Krider RE (2002) Barriers to the advancement of modern food retail formats: theory and measurements. J Food Retail 78, 281-295.

9. Stamoulis K, Pingali P \& Shetty P (2004) Emerging challenges for food and nutrition policy in developing countries. J Agric Dev Econ 1, 154-167.

10. Morland KB \& Evenson KR (2009) Obesity prevalence and the local food environment. Health Place 15, 491-495.

11. Aounallah-Skhiri H, Romdhane HB, Traissac P et al. (2008) Nutritional status of Tunisian adolescents: associated gender, environmental and socio-economic factors. Public Health Nutr 11, 1306-1317.

12. Beltaifa L, Traissac P, El Ati J et al. (2009) Prevalence of obesity and associated socioeconomic factors among Tunisian women from different living environments. Obes Rev 10, 145-153.

13. Tessier S, Traissac P, Maire B et al. (2008) Regular users of supermarkets in Greater Tunis have a slightly improved diet quality. J Nutr 138, 768-774. 
14. United Nations Development Programme, (editor) (2007) Human Development Report 2007/2008. New York: UNDP.

15. Institut National de la Statistique (2004) Annuaire statistique de la Tunisie No. 47. Tunis: Ministère du développement et de la Coopération Internationale.

16. US Department of Agriculture, Foreign Agricultural Service (2005) Tunisia. Retail Food Sector. GAIN Report no. TS5011. Washington, DC: USDA.

17. Levy PS \& Lemeshow S (1999) Sampling of Populations. Methods and Applications, 3rd ed. New York: John Wiley \& Sons.

18. Greenacre MJ (2007) Correspondence Analysis in Practice, 2nd ed. Boca Raton, FL: Chapman \& Hall/CRC.

19. Delpeuch F, Cornu A, Massamba JP et al. (1994) Is body mass index sensitively related to socio-economic status and to economic adjustment? A case study from the Congo. Eur J Clin Nutr 48, Suppl. 3, S141-S147.

20. Hosmer DW \& Lemeshow S (2000) Applied Logistic Regression, 2nd ed. New York: John Wiley \& Sons.

21. Korn EL \& Graubard BI (1999) Analysis of Health Surveys. New York: John Wiley \& Sons Inc.

22. Neven D, Reardon T, Chege J et al. (2006) Supermarkets and consumers in Africa - the case of Nairobi, Kenya. J Int Food Agribus Mark 18, 103-123.

23. Mission Economique de Tunis, Tunisie (2006) La distribution agroalimentaire en Tunisie. Tunis: UBIFRANCE.

24. Reardon T \& Berdegue JA (2006) The Retail-Led Transformation of Agrifood Systems and its Implications for Development Policies - A Background Paper Prepared for the World Bank's World Development Report 2008: Agriculture for Development. Santiago: Rimisp, Latin American Center for Rural Development.
25. Porter G, Lyon F, Potts D et al. (2004) Improving market institutions and urban food supplies for the urban poor: a comparative study of Nigeria and Zambia: scoping phase. Literature review R8330. http://www.dur.ac.uk/nigerian. marketing/Improving\%20market\%institutions\%and\%urban \%food\%supplies.pdf (accessed December 2008).

26. Desjeux D (2003) La cathédrale, le caddie et la caméra: les voies cachées de l'institutionnalisation de la consommation. Agrobiosciences Almanach 2003, 72-75.

27. Beaulac J, Kristjansson E \& Cummins S (2009) A systematic review of food deserts, 1966-2007. Prev Chronic Dis 6, A105.

28. Cummins S \& Macintyre S (2002) 'Food deserts' - evidence and assumption in health policy making. BMJ 325, 436-438.

29. Cummins S, Petticrew M, Sparks L et al. (2005) Large scale food retail interventions and diet. BMJ 330, 683-684.

30. Murakami K, Sasaki S, Takahashi Y et al. (2009) Neighborhood food store availability in relation to food intake in young Japanese women. Nutrition 25, 640-646.

31. Song HJ, Gittelsohn J, Kim M et al. (2009) A corner store intervention in a low-income urban community is associated with increased availability and sales of some healthy foods. Public Health Nutr 12, 2060-2067.

32. Rothman KJ \& Greenland S (1998) Modern Epidemiology. Philadelphia, PA: Lippincott Williams and Wilkins.

33. Minten B (2008) The food retail revolution in poor countries: is it coming or is it over? Econ Dev Cult Change 56, 767-789.

34. Asfaw A (2008) Does supermarket purchase affect the dietary practices of households? Some empirical evidence from Guatemala. Dev Policy Rev 26, 227-243. 